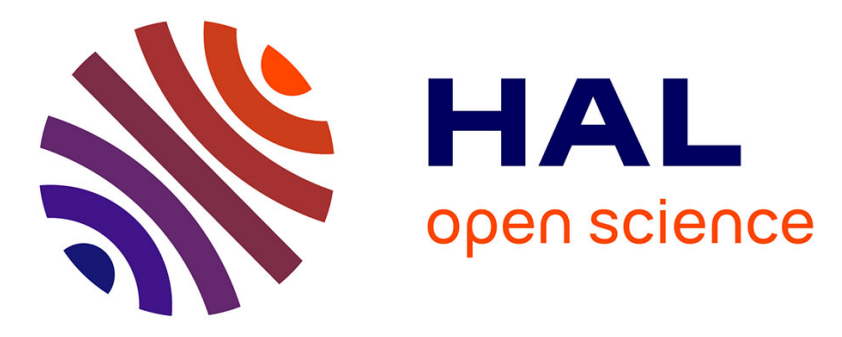

\title{
Total synthesis and biological assessment of novel albicidins discovered by mass spectrometric networking
}

Leonard von Eckardstein, Daniel Petras, Tam Dang, Stéphane Cociancich, Souhir Sabri, Stefan Grätz, Dennis Kerwat, Maria Seidel, Alexander Pesic,

Pieter C. Dorrestein, et al.

\section{To cite this version:}

Leonard von Eckardstein, Daniel Petras, Tam Dang, Stéphane Cociancich, Souhir Sabri, et al.. Total synthesis and biological assessment of novel albicidins discovered by mass spectrometric networking. Chemistry - A European Journal, 2017, 23 (61), pp.1-6. 10.1002/chem.201704074 . hal-01608574

\section{HAL Id: hal-01608574 \\ https://hal.science/hal-01608574}

Submitted on 26 May 2020

HAL is a multi-disciplinary open access archive for the deposit and dissemination of scientific research documents, whether they are published or not. The documents may come from teaching and research institutions in France or abroad, or from public or private research centers.
L'archive ouverte pluridisciplinaire HAL, est destinée au dépôt et à la diffusion de documents scientifiques de niveau recherche, publiés ou non, émanant des établissements d'enseignement et de recherche français ou étrangers, des laboratoires publics ou privés.

\section{다(1)(2)}

Distributed under a Creative Commons Attribution - ShareAlikel 4.0 International 


\title{
Total synthesis and biological assessment of novel albicidins discovered by mass spectrometric networking
}

\author{
Leonard von Eckardstein, ${ }^{\#[a]}$ Daniel Petras, ${ }^{\#[a, b]}$ Tam Dang, ${ }^{[a]}$ Stéphane Cociancich, ${ }^{[c, d]}$ Souhir Sabri, ${ }^{[c, d]}$ \\ Stefan Grätz, ${ }^{[a]}$ Dennis Kerwat, ${ }^{[a]}$ Maria Seidel, ${ }^{[a]}$ Alexander Pesic, ${ }^{[a]}$ Pieter C. Dorrestein, ${ }^{[b]}$ \\ Monique Royer, ${ }^{[c, d]}$ John B. Weston, ${ }^{[a]}$ and Roderich D. Süssmuth ${ }^{*[a]}$
}

\begin{abstract}
Natural products represent an important source of potential novel antimicrobial drug leads. Low production by microorganisms in cell culture often delays the structural elucidation or even prevents a timely discovery. Starting from the anti-Gram-negative antibacterial compound albicidin produced by Xanthomonas albilineans, we describe a bioactivity-guided approach combined with non-targeted tandem mass spectrometry and spectral (molecular) networking for the discovery of novel antimicrobial compounds. We report eight new natural albicidin derivatives, four of which bear a $\beta$-methoxy cyanoalanine or $\beta$-methoxy asparagine as the central $\alpha$-amino acid. We present the total synthesis of these albicidins, which facilitated the unambiguous determination of the $(2 S, 3 R)$-stereoconfiguration which is complemented by the assessment of the stereochemistry on antibacterial activity.
\end{abstract}

Antibiotic resistance is one of the major challenges in the current treatment of bacterial infections which represents one of the greatest threats to global human health. ${ }^{[1,2]}$ This encourages scientists to develop novel therapeutic approaches, including the search for new antibacterial compounds. ${ }^{[3]}$ A typical problem in natural product discovery are low production yields in cell culture, leading to low amounts of the target compound available for de novo structural elucidation. A prominent example is the structural elucidation of the anti-Gram-negative compound albicidin (1) synthesized by the sugarcane pathogenic bacterium Xanthomonas albilineans. ${ }^{[4,5]}$ The low production forced us to transfer albicidin biosynthesis genes in a heterologous host and

[a] L. von Eckardstein, Dr. D. Petras, T. Dang, Dr. S. Grätz, D. Kerwat, M. Seidel, Dr. A. Pesic, Dr. J. B. Weston, Prof. Dr. R. D. Süssmuth Institut für Chemie

Technische Unitersität Berlin

Straße des 17. Juni 124, 10623 Berlin, Germany

E-mail: suessmuth@chem.tu-berlin.de

[b] Dr. D. Petras, Prof. Dr. P. C. Dorrestein

Skaggs School of Pharmacy and Pharmaceutical Sciences University of California, San Diego

9500 Gilman Drive, La Jolla, CA 92093, USA

[c] Dr. S. Cociancich, Dr. M. Royer, Dr. S. Sabri CIRAD, UMR BGPI, F-34398 Montpellier, France

[d] Dr. S. Cociancich, Dr. M. Royer, Dr. S. Sabri

BGPI, Univ. Montpellier, CIRAD, INRA, Montpellier SupAgro, Montpellier, France

\# These authors contributed equally to this work.

Supporting information for this article (including experimental details) is available online. to cultivate hundreds of liters to obtain ${ }^{15} \mathrm{~N}$-labelled material required for the NMR experiments. ${ }^{[4]}$ The structure of albicidin (Figure 2) consists of differently substituted $p$-aminobenzoic acids a central $\beta$-cyano alanine and an $\mathrm{N}$-terminal substituted cinnamic acid. Hence, for a comprehensive understanding of crucial pharmacophoric regions, we developed a total synthesis for albicidin, ${ }^{[6]}$ which enabled structure-activity-relationship studies. ${ }^{[7-}$ 9]

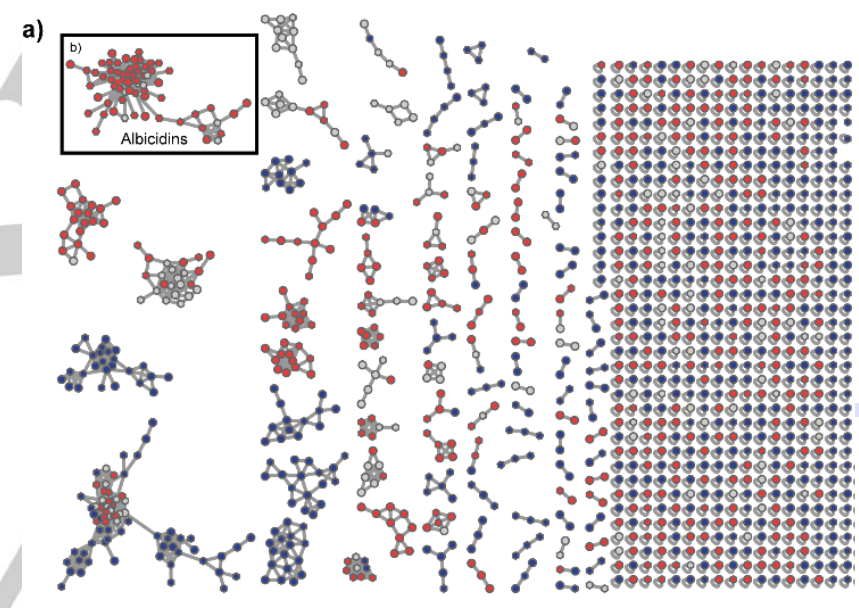

b)

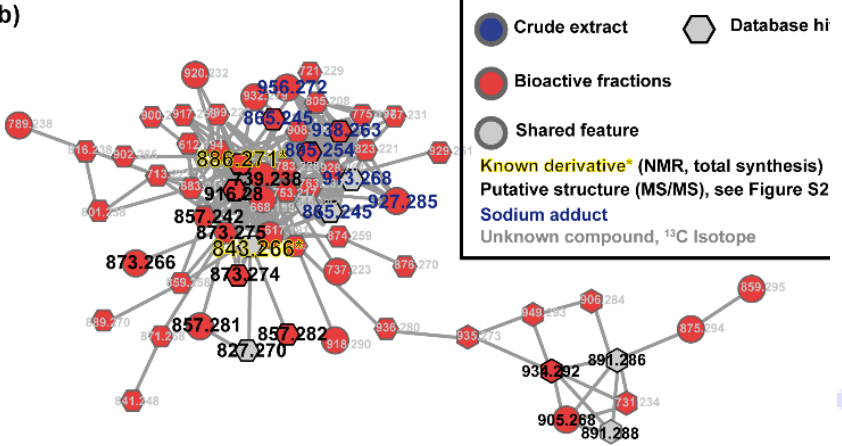

Figure 1 a) Mass spectrometric molecular network analysis of crude extract and bioactive fractions produced by $\boldsymbol{X}$. albilineans. The molecular network was created with GNPS ${ }^{[10]}$ and visualized with Cytoscape. ${ }^{[12]}$ Every node represents a unique or a set of consensus spectra. Similar MS/MS spectra (nodes) are connected through lines and form molecular networks - spectra from the crude extract (blue) and from bioactive fractions (red) as well as spectra from both crude extract and bioactive fractions (grey). Hexagonal nodes represent spectra which show similarity to one or more library spectra. b) Subnetwork of albicidin and its derivatives. Black label indicates annotated spectra with a putative chemical structure, blue label shows spectra which originate from sodium adducts. Nodes labelled in grey represent either MS/MS spectra of ${ }^{13} \mathrm{C}$ isotope peaks or of unknown compounds. 


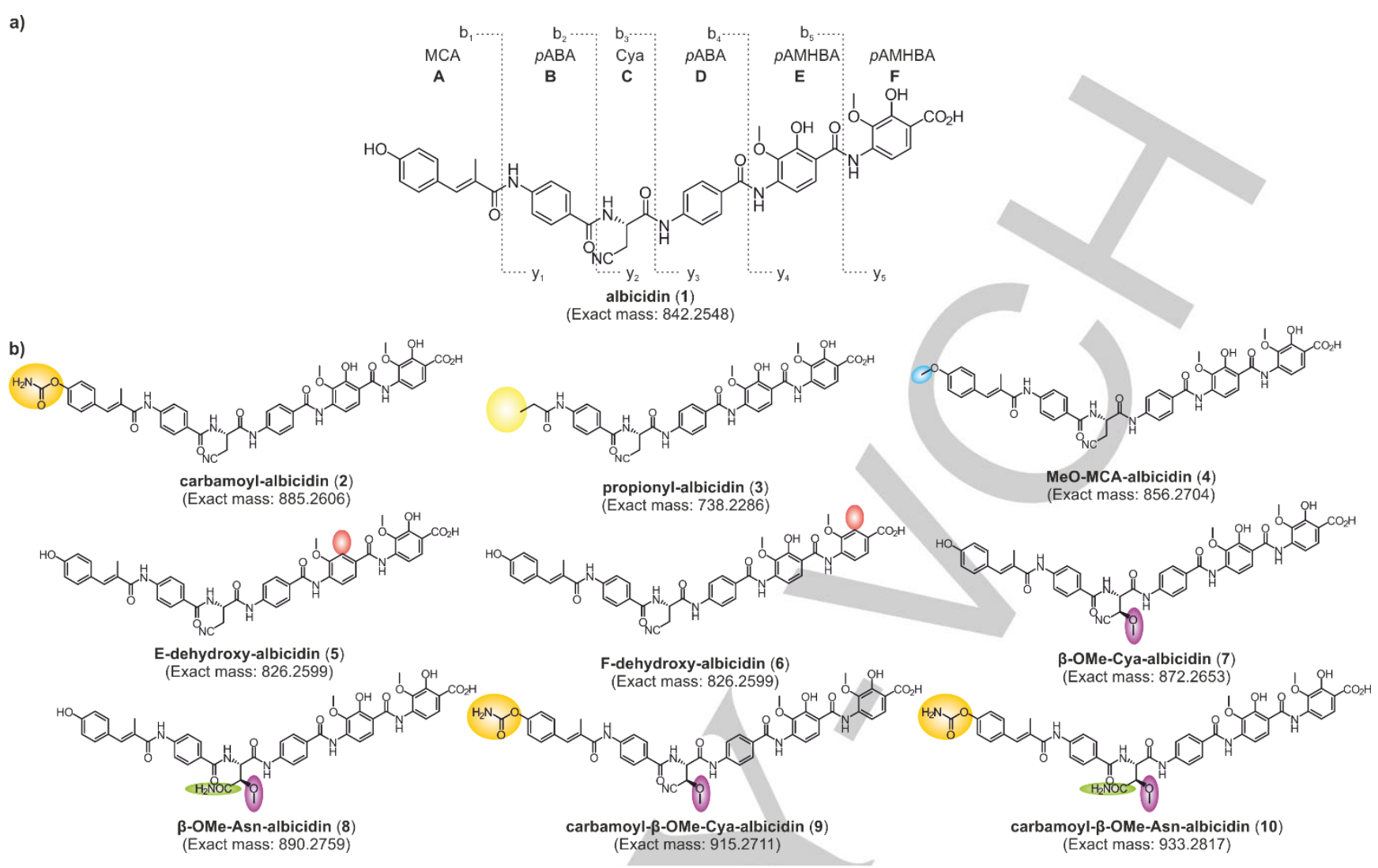

Figure 2 Structures of albicidin and albicidin derivatives from $\boldsymbol{X}$. albilineans. Modifications are indicated: carbamoylation (orange), truncated building block A (yellow), dehydroxylation (red), methylation (blue), methoxylation (purple) and nitrile to amide exchange conversion (green).

Here we present the discovery of eight new albicidins from Xanthomonas through a non-targeted LC-MS/MS approach combined with spectral networking using Global Natural Product Social Molecular Networking (GNPS), a recently introduced platform for MS/MS data analysis. ${ }^{[10]}$ The mass spectrometric structure elucidation was followed by a subsequent total synthesis and an antibacterial profiling of the synthetic derivatives.

For the mass spectrometric analysis of culture extracts from $X$. albilineans, we implemented a bioactivity-guided pre-purification by solid phase extraction (SPE) and semi-preparative HPLC. The HPLC fractions with antibacterial activity were subsequently submitted to LC-MS/MS analysis. The application of this workflow (cf. supporting information, SI) rendered a series of new albicidin derivatives of which structures were deduced based on exact mass and MS/MS fragmentation patterns.

Antibacterial activity was observed from HPLC-fractions (SI) at retention times of 6.6-7.6 min with the biggest inhibition zone at $7.4 \mathrm{~min}$ (retention time of albicidin). A shoulder in the bioactivity chromatogram at $6.8 \mathrm{~min}$ indicated further bioactive compounds. Hence, these fractions were submitted to non-targeted LCMS/MS. With approximately 2,000 MS/MS spectra per fraction, we generated $>20,000$ spectra in total. To facilitate the MS/MS data analysis, we performed spectral networking using GNPS. ${ }^{[10]}$ Hence, identical MS/MS spectra are combined and consensus spectra are compared to each other as well as to a spectral library. Consensus spectra are then visualized as nodes, which are connected to other nodes depending on their spectral

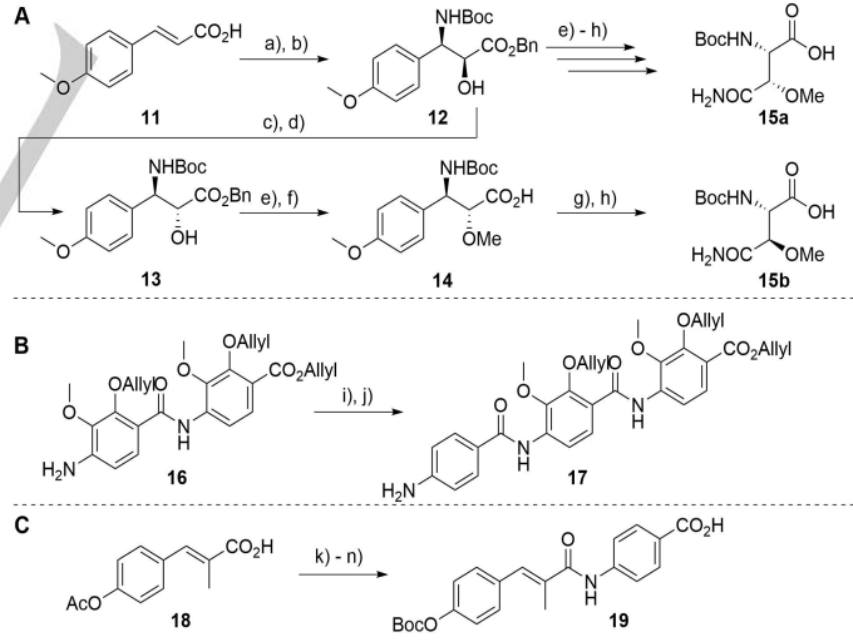

Scheme 1 Reagents and conditions. A synthesis of building block $\mathrm{C}$ : a) oxalyl chloride, DMF, DCM, rt, $1 \mathrm{~h}$ then pyridine, $\mathrm{BnOH}$, rt, $3 \mathrm{~h}, 92 \%$ b) $\mathrm{tBuOCONH}_{2}$, tBuOCl, (DHQD) ${ }_{2} \mathrm{PHAL}, \mathrm{K}_{2}\left[\mathrm{OsO}_{2}(\mathrm{OH})_{4}\right], \mathrm{NaOH}, n \mathrm{PrOH} / \mathrm{H}_{2} \mathrm{O}(2: 1), 0{ }^{\circ} \mathrm{C}, 1.5 \mathrm{~h}$, $85 \%$, ee $99 \%$; c) pNBA, $\mathrm{PPh}_{3}, \mathrm{DEAD}, \mathrm{THF}, \mathrm{rt}, 16 \mathrm{~h}$ d) $\mathrm{NaN}_{3}, \mathrm{MeOH}, 45^{\circ} \mathrm{C}$, $6 \mathrm{~h}, 85 \%$ over two steps, e) $\mathrm{Ag}_{2} \mathrm{O}, \mathrm{CH}_{3} \mathrm{l}, \mathrm{DCM}, \mathrm{rt}, 16 \mathrm{~h}, 92-93 \%$; f) $10 \% \mathrm{Pd} / \mathrm{C}$, $\mathrm{H}_{2}, \mathrm{MeOH}$, rt, $\left.5 \mathrm{~h}, 93-96 \% ; \mathrm{g}\right) \mathrm{Boc}_{2} \mathrm{O}, \mathrm{NH}_{4} \mathrm{HCO}_{3}$, pyridine, dioxane, rt, $16 \mathrm{~h}$, $79-83 \%$; h) $\mathrm{RuCl}_{3}, \mathrm{NalO}_{4}, \mathrm{CH}_{3} \mathrm{CN} / \mathrm{EtOAc} / \mathrm{H}_{2} \mathrm{O}$ (1:1:4), rt, $6 \mathrm{~h}, 52-55 \%$; B synthesis of DEF: i) pNBA-Cl, DIPEA, THF, rt, $3 \mathrm{~h}, 87 \%$; j) $\mathrm{Zn}, \mathrm{AcOH}, \mathrm{EtOH}$, rt, $1 \mathrm{~h}, 97 \%$; C synthesis of $\mathrm{AB}: \mathrm{k}$ ) $\mathrm{SOCl}_{2}$, toluene, $120^{\circ} \mathrm{C}, 2 \mathrm{~h}$, quant.; I) pABAOMe, DIPEA, THF, rt, 3 h, $86 \%$ m) KOH, MeOH/THF/ $\mathrm{H}_{2} \mathrm{O}(2: 1: 1)$, rt, 1 h, $96 \%$; n) $\mathrm{Boc}_{2} \mathrm{O}, \mathrm{K}_{2} \mathrm{CO}_{3}, \mathrm{DMAP}, \mathrm{THF} / \mathrm{H}_{2} \mathrm{O}(2: 1)$, rt, 2 h, $94 \%$. 


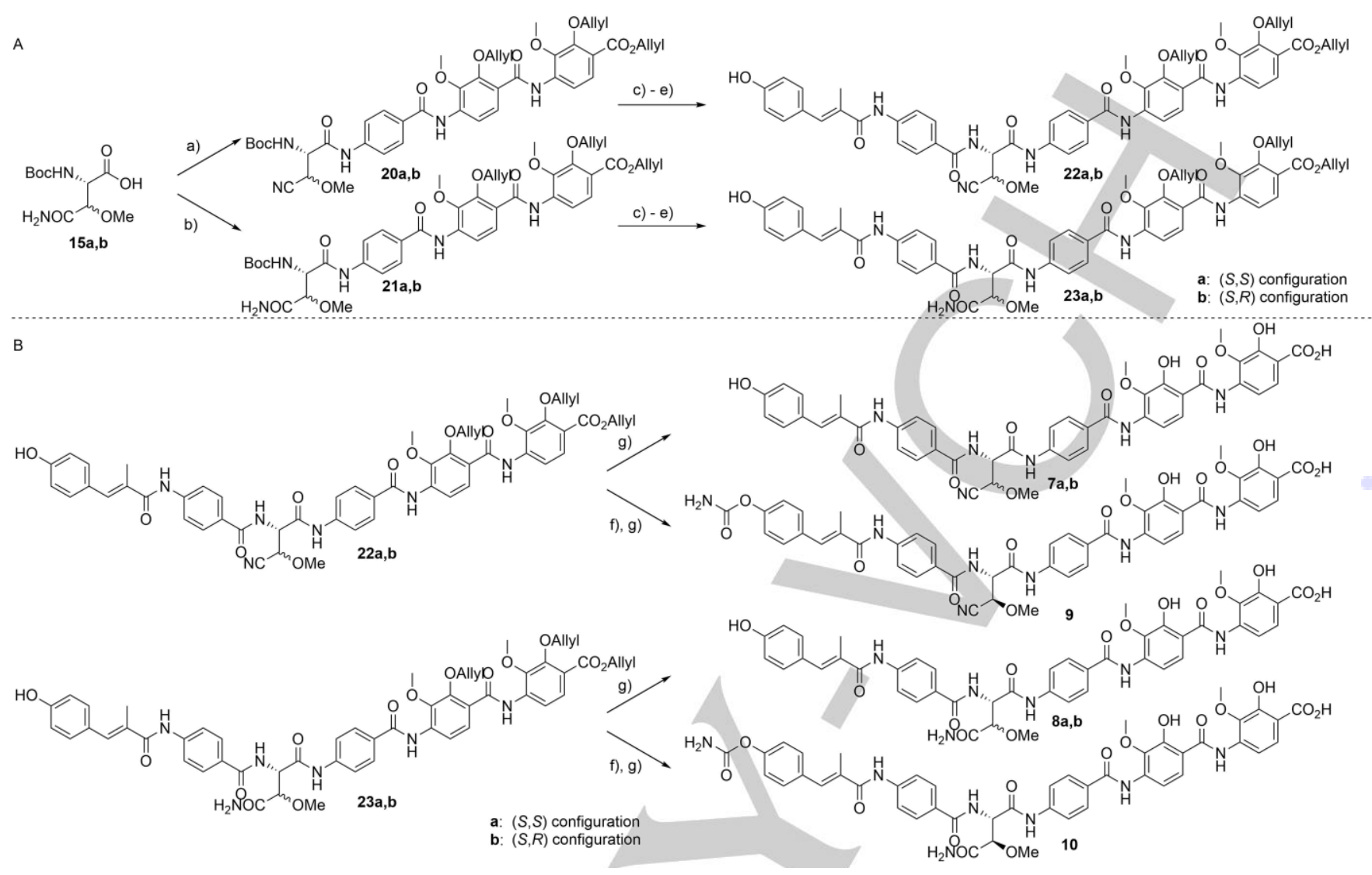

Scheme 2 Reagents and conditions. A assembly of protected albicidins: a) 15a or b, EEDQ, DMF, $0{ }^{\circ} \mathrm{C}->\mathrm{rt}, 16 \mathrm{~h}, 49-51 \%$; b) $\mathrm{EEDQ}, \mathrm{CHCl}, 0{ }^{\circ} \mathrm{C}->\mathrm{rt}, 16$ 51-55 \%; c) formic acid, rt, 2 h, 96-99 \% d) HATU, DIPEA, rt, 3 h, 74-78 \% e) formic acid, rt, 1 h, 93 \% B carbamoylation and global deprotection: f) CSI, DCM, rt, 3 quant. (crude) g) $\left[\mathrm{Pd}\left(\mathrm{PPh}_{3}\right)_{4}\right]$, phenylsilane, THF, $8 \mathrm{~h}, 25-51 \%$.

similarity. The so formed networks show clusters of similar spectra and thus most likely similar chemical structures. ${ }^{[10-12]}$ The molecular network of all MS/MS spectra and a subnetwork of 65 nodes including albicidin is shown in Figure 1.58 consensus MS/MS spectra in the subnetwork (Figure 1b) arose exclusively from bioactive fractions (red nodes). Seven nodes originate from both, bioactive fractions and crude extract (grey nodes). As the network also contains MS/MS spectra of adduct ions, e.g. $[\mathrm{M}+\mathrm{Na}]^{+}$(blue labels), and ${ }^{13} \mathrm{C}$ isotope peaks (grey labels), not all 65 nodes represent an individual derivative. As most of the spectra were only acquired from bioactive fractions, this indicates that pre-purification of the crude extract was crucial for discovery. After identification of potential derivatives in the subnetwork, the particular MS/MS spectra and exact masses were manually analyzed (annotated nodes labeled in black font).

Product ion spectra with collision-induced dissociation (CID or HCD, shown in Figure S2, Table S1) of albicidin typically rendered the formation of $b$ - and $y$-ion series. Apart from albicidin $1\left([\mathrm{M}+\mathrm{H}]^{+}=843.262 \mathrm{Da}\right)^{[4]}$ and carbamoyl albicidin 2 $\left([\mathrm{M}+\mathrm{H}]^{+}=886.268 \mathrm{Da}\right),{ }^{[13]}$ we were able to propose structures of eight putative albicidin derivatives (Figure 2 and $\mathrm{SI}$ ): for propionyl-albicidin $3\left([\mathrm{M}+\mathrm{H}]^{+}=739.236 \mathrm{Da}\right)$, a propionyl residue replaces 2-methylcoumaric acid (MCA) and methoxy-MCAalbicidin in the case of $4\left([\mathrm{M}+\mathrm{H}]^{+}=857.278 \mathrm{Da}\right)$ is a methylated albicidin $(+14.016 \mathrm{Da})$. Two further derivatives $\left([\mathrm{M}+\mathrm{H}]^{+}=827.267\right.$ $\mathrm{Da}$ ) bear 4-amino-3-methoxybenzoic acid (pAMBA) instead of the tetrasubstituted 4-amino-2-hydroxy-3-methoxybenzoic acid (pAMHBA) at building blocks $E(5)$ and $F(6)$. The likely most interesting modification is located in the central $\alpha$-amino acid: a mass shift of $+30.011 \mathrm{Da}$ corresponds to a methoxy or a hydroxymethyl group suggesting a putative $\beta$-OMe-Cya-albicidin $7\left([\mathrm{M}+\mathrm{H}]^{+}=873.273 \mathrm{Da}\right)$ and a mass shift of $+48.023 \mathrm{Da}$ fits $\beta$ OMe-Asn-albicidin $8\left([\mathrm{M}+\mathrm{H}]^{+}=891.283 \mathrm{Da}\right)$, which ultimately could be confirmed by isolation of $\sim 0.1 \mathrm{mg}$ rendering a ${ }^{1} \mathrm{H}-\mathrm{NMR}$ spectrum for structure elucidation (Figure 3 ). Finally, both, 7 and 8 were additionally found with a putative $O$-carbamoylation at the $\mathrm{N}$-terminus: carbamoyl- $\beta$-OMe-Cya-albicidin $9\left([\mathrm{M}+\mathrm{H}]^{+}=916.278\right.$ Da) and carbamoyl- $\beta$-OMe-Asn-albicidin $10\left([\mathrm{M}+\mathrm{H}]^{+}=934.289\right.$ $\mathrm{Da})$. 
Table 1 Antibacterial activity of albicidin (1), its derivatives (3-10) and synthetic cystobactamid/coralmycin analogues (24a-24d). Minimal inhibitory concentrations (MIC) are given in $\mu \mathrm{g} / \mathrm{mL} .{ }^{[8]}$

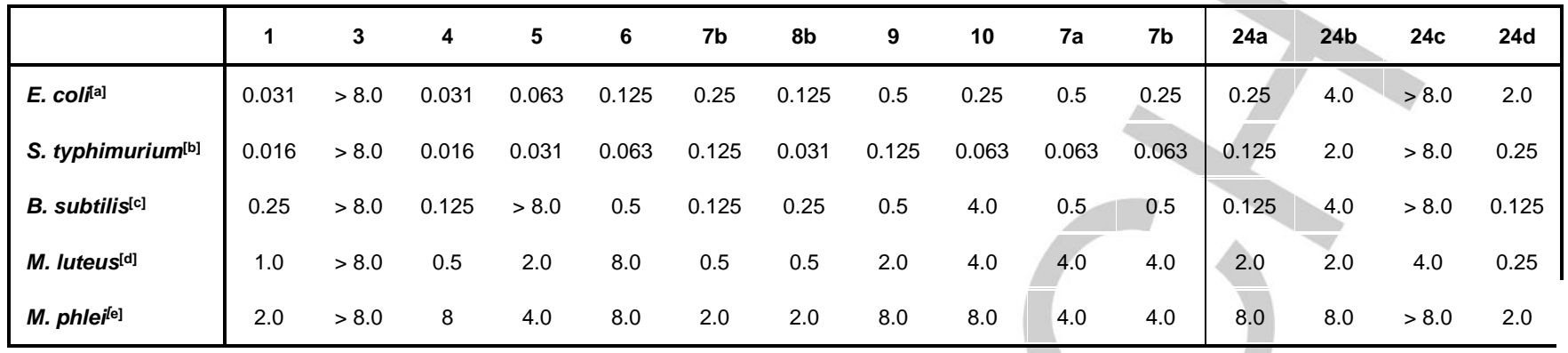

[a] E. coli BW25113, [b] S. typhimurium TA100, [c] B. subtilis DSM10, [d] M. luteus DSM1790, [e] M. phlei DSM750

To unambiguously confirm the structures of the eight new derivatives of albicidin, a total synthesis was envisaged. The main challenge was the syntheses of the $\beta$-OMe-Cya- and of the $\beta$ OMe-Asn-albicidins. We decided to synthesize both enantiomers of L- $\beta$-OMe-Asn, since the stereoconfiguration at the a-position was already known ${ }^{[6]}$ while the configuration at the $\beta$-position introduced by the $\beta$-hydroxylating oxygenase Alb08 was unclear. The retrosynthetic analysis was based on a $(A B+C+D E F)$ coupling strategy using allyl protecting groups and an assembly of $\beta$-hydroxy amino acids via the Sharpless asymmetric aminohydroxylation (AA). Starting material was cinnamic acid derivative 11 (Scheme $1 A$ ), followed by the oxidative degradation of the aromatic functionality to give the carboxylic acid. ${ }^{[14,15]}$ However, in order to avoid strong basic or acidic conditions that could easily lead to racemization, we chose the benzyl ester to allow an orthogonal liberation of the carboxylic acid that could easily be converted to the corresponding amide. Even if there are no reports of the Sharpless AA in combination with benzyl esters, the desired regioisomer 12 was obtained in good yield and enantioselectivity. In order to obtain the other desired stereoisomer 13, the configuration at the $\beta$-position was inverted by a Mitsunobu reaction using $p$-nitrobenzoic acid ( $p N B A$ ) followed by selective ester hydrolysis with $\mathrm{NaN}_{3}{ }^{[16]}$ The resulting protected amino alcohol $\mathbf{1 3}$ was methylated, followed by hydrogenolytic deprotection of the benzyl ester to give 14 . The resulting carboxylic acids were converted to the corresponding amides $^{[17]}$ and unmasking of the carboxylic acid with in situ

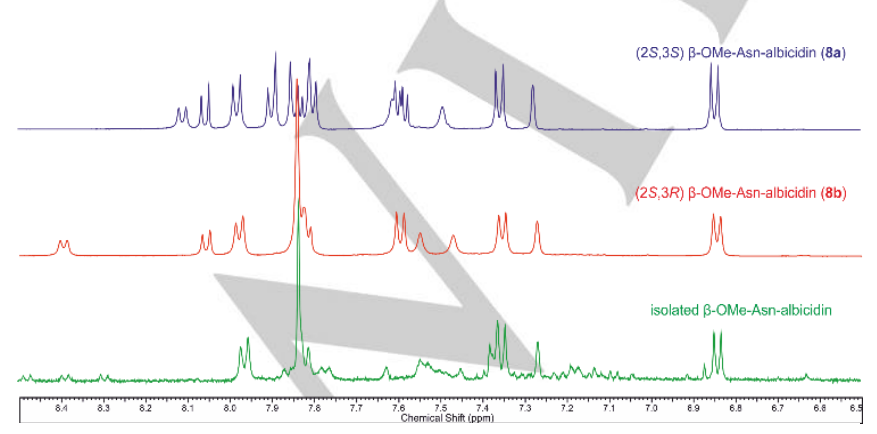

Figure 3 Determination of the stereoconfiguration of the central $\alpha$-amino acid. Comparison of the aromatic region of the ${ }^{1} \mathrm{H}-\mathrm{NMR}$ spectra $(500 \mathrm{MHz}$, DMSO- $d_{6}$ ) of synthetic $\mathbf{8} \mathbf{a}$, diastereomer $\mathbf{8 b}$ and natural $\beta$-OMe-Asn-albicidin.

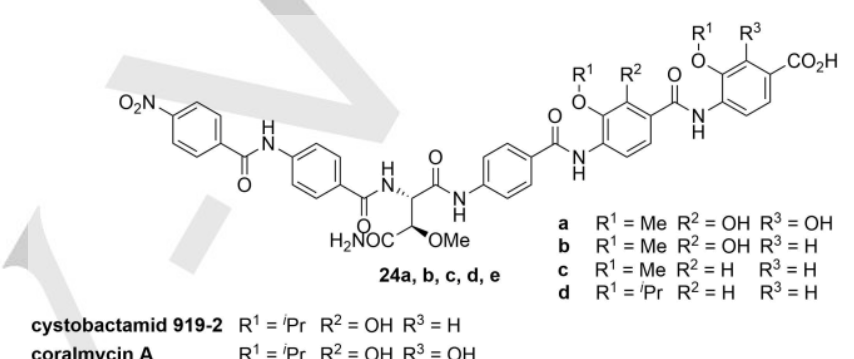

$\mathrm{R}^{1}=\mathrm{i}_{\mathrm{Pr}} \mathrm{R}^{2}=\mathrm{OH} \mathrm{R}^{3}=\mathrm{OH}$

Figure 4 Structure of cystobactamid analogues. The analogues of cystobactamid were synthesized to study the influence of the N-terminal $p$ NBA vs. $M C A$, the substitution pattern at $E F\left(R^{2}, R^{3}\right)$ and the substitution at $R^{1}$.

generated $\mathrm{RuO}_{4}{ }^{[18]}$ afforded the desired Boc-protected amino acids $(2 S, 3 S)$ - (15a) and $(2 S, 3 R)-\beta-O M e-A s n(15 \mathbf{b})$.

In the present synthesis, we changed the original coupling strategy $(A B+C+D E F \text { instead of } A+B C D+E F)^{[6]}$ in order to integrate the precious $\alpha$-amino acid at a late step in the synthesis. Because of this, $\beta$-OMe-Asn was coupled with the C-terminal tripeptide 17 (DEF), followed by coupling of an orthogonally protected MCA-pABA (19, Schemes 1 and 2). While the preparation of the tripeptide $\mathbf{1 7}$ could be easily accomplished in two steps, the coupling of the a-amino acid was much more challenging. The low nucleophilicity of the aniline requires highly activated intermediates such as anhydrides or acyl chlorides. However, the latter are known to be highly prone to racemization. ${ }^{[19]}$ Fortunately, the herein used coupling reagent EEDQ is known for its low rates of racemization while forming highly reactive mixed anhydrides. ${ }^{[20]}$ Furthermore, the rate of dehydration of the Asn side chain proved to be highly dependent on the polarity of the solvent. This allowed the controlled synthesis of either $\beta$-OMe-Cya or $\beta$-OMe-Asn to yield the four tetrapeptides $20 \mathrm{a} / \mathrm{b}$ and $21 \mathrm{a} / \mathrm{b}$. Because $\beta$-OMe-Cya proved to be particularly unstable under strong acidic conditions, TFA was substituted by formic acid for the following Boc-deprotection. The resulting amines could be reacted with the previously prepared Bocprotected MCA-pABA (19) using HATU. Then, the Boc-groups were selectively removed to yield $22 \mathbf{a} / \mathbf{b}$ and $23 \mathbf{a} / \mathbf{b}$ which could either be first carbamoylated using chlorosulfonyl isocyanate (CSI) or directly globally deprotected. After HPLC purification, albicidins $\mathbf{7 a}, \mathbf{8 a}, \mathbf{9}, \mathbf{1 0}$ and their diastereomers $\mathbf{7 b}$ and $\mathbf{8 b}$ were obtained (for synthesis of 3-6, cf. SI). 
The comparison of the MS/MS spectra of the synthetic derivatives 3-10 with the corresponding spectra from the spectral networking approach proved that the postulated structures are correct (cf. SI). Notably, the aromatic regions of the NMR spectra of the two diastereomers $\mathbf{8 a}$ and $\mathbf{8 b}$ of $\beta$-OMe-Asn-albicidin differ remarkably (Figure 3). The comparison with a low concentrated NMR sample of isolated $\beta$-OMe-Asn-albicidin 8 unambiguously confirmed the natural configuration as $2 S, 3 R$.

Taking into account that $\beta$-OMe-Asn is also the central building block of related compounds, cystobactamid and coralmycin, we synthesized four analogues (24a-d, Figure 4) to study the influence of the N-terminal pNBA building block, of isopropyl substituents and of the hydroxylation pattern at the rings $D$ and $E$ on bioactivity. In general, we followed the same synthesis strategy as for the albicidins. However, the synthesis of $\mathbf{2 4 c}$ and $\mathbf{d}$ required an inverted protecting group strategy due to instability and solubility issues (for an alternative protocol to $\beta$-OMe-Asn, and its implementation $c f$. SI).

Finally, the MIC values for all synthetic albicidins and cystobactamid/coralmycin analogues were compared against several Gram-positive and Gram-negative bacteria (Table 1). While all of the derivatives proved to be active, the natural $(2 S, 3 R)$-configured derivatives mostly showed slightly higher activity than the corresponding diastereomers. An N-terminal aromatic group (MCA/pNBA) seems to be crucial for the activity, since propionyl-albicidin $\mathbf{3}$ is completely inactive. ${ }^{[9]}$ Furthermore, a higher substitution of the two C-terminal building blocks seems to increase the activity (cf. albicidins $\mathbf{1 + 4}$ vs. $\mathbf{5 + 6}$ and cystobactamid-type $\mathbf{2 4 a}$ vs. $\mathbf{2 4 b}$ vs. 24c) as earlier suggested by Kim et al. ${ }^{[21]}$ In comparison to the analogues 24a-d, MCA seems to be beneficial for antimicrobial activity (cf. 8b vs. 24a) over $p$ NBA. Finally, the isopropyl group at ring $E$ can restore bioactivity for a lack in substituents at rings $E$ and $F(24 c$ vs. 24d).

In conclusion, the application of our bioactivity-guided spectral networking workflow shows high potential for future natural product discovery studies. The combination of bioactivity-guided selection, non-targeted high-throughput analysis using LC-MS/MS and bioinformatic data analysis will push the molecular search for bioactive and novel compounds to the scale of contemporary genomic and meta-genomic studies. The total synthesis of the new albicidin derivatives, including two diastereomers of the non-proteinogenic amino acid $\beta$-OMe-Asn, is paralleled by independent studies from the Kirschning ${ }^{[22]}$ and the Trauner ${ }^{[23]}$ groups. Unlike their synthesis protocols, our approach allowed for the direct synthesis of L- $\beta$-OMe-Asn in both stereoconfigurations. Hence, our protocol also avoids racemization-prone intermediates as acyl chlorides ${ }^{[22]}$ or late stage aminolysis steps over easily racemizable aspartimides. ${ }^{[23,24]}$ Furthermore, the new coupling strategy allows the efficient synthesis of further building block $C$ variants. ${ }^{[8]}$ Finally, the comparison of results for four synthetic analogues gave further insight into the structure-activity relationships of albicidins and cystobactamid/coralmycins in the search for a new class of antibiotic agents.

\section{Experimental Section}

Detailed experimental procedure, synthetic protocols and additional spectroscopic data can be found in the Supporting Information (SI).

\section{Acknowledgements}

This work was supported by grants from the Deutsche Forschungsgemeinschaft (DFG, SU 239/11-1 and PE 2600/1-1), the BMBF (VIP grant) and the Agence Nationale de la Recherche (ANR-09-BLANC-0413-01).

Keywords: albicidin $\cdot$ molecular networking $\bullet$ total synthesis $•$ antibiotic $\cdot$ bioactivity screening

[1] S. C. Davies, T. Fowler, J. Watson, D. M. Livermore, D. Walker, The Lancet 2013, 381, 1606-1609.

[2] J. M. A. Blair, M. A. Webber, A. J. Baylay, D. O. Ogbolu, L. J. V. Piddock, Nat. Rev. Microbiol. 2015, 13, 42-51.

[3] C. W. Johnston, N. A. Magarvey, Nat. Chem. Biol. 2015, 11, 177-178.

[4] S. Cociancich, A. Pesic, D. Petras, S. Uhlmann, J. Kretz, V. Schubert, L. Vieweg, S. Duplan, M. Marguerettaz, J. Noëll, et al., Nat. Chem. Biol. 2015, 11, 195-197.

[5] R. Süssmuth, J. Kretz, V. Schubert, A. Pesic, M. Hügelland, M. Royer S. Cociancich, P. Rott, D. Kerwat, S. Grätz, Albicidin Derivatives, Their Use and Synthesis, 2014, WO/2014/125075.

[6] J. Kretz, D. Kerwat, V. Schubert, S. Grätz, A. Pesic, S. Semsary, S. Cociancich, M. Royer, R. D. Süssmuth, Angew. Chem. Int. Ed. 2015, 54, 1969-1973.

[7] L. Vieweg, J. Kretz, A. Pesic, D. Kerwat, S. Grätz, M. Royer, S. Cociancich, A. Mainz, R. D. Süssmuth, J. Am. Chem. Soc. 2015, 137, 7608-7611.

[8] S. Grätz, D. Kerwat, J. Kretz, L. von Eckardstein, S. Semsary, M. Seidel, M. Kunert, J. B. Weston, R. D. Süssmuth, ChemMedChem 2016, 11, 1499-1502.

[9] D. Kerwat, S. Grätz, J. Kretz, M. Seidel, M. Kunert, J. B. Weston, R. D. Süssmuth, ChemMedChem 2016, 11, 1899-1903.

[10] M. Wang, J. J. Carver, V. V. Phelan, L. M. Sanchez, N. Garg, Y. Peng, D. D. Nguyen, J. Watrous, C. A. Kapono, T. Luzzatto-Knaan, et al., Nat. Biotechnol. 2016, 34, 828-837.

[11] J. Watrous, P. Roach, T. Alexandrov, B. S. Heath, J. Y. Yang, R. D. Kersten, M. van der Voort, K. Pogliano, H. Gross, J. M. Raaijmakers, et al., Proc. Natl. Acad. Sci. 2012, 109, E1743-E1752.

[12] P. Shannon, A. Markiel, O. Ozier, N. S. Baliga, J. T. Wang, D. Ramage, N. Amin, B. Schwikowski, T. Ideker, Genome Res. 2003, 13 , 2498-2504.

[13] D. Petras, D. Kerwat, A. Pesic, B.-F. Hempel, L. von Eckardstein, S. Semsary, J. Arasté, M. Marguerettaz, M. Royer, S. Cociancich, et al., ACS Chem. Biol. 2016, 11, 1198-1204.

[14] D. L. Boger, R. J. Lee, P. Y. Bounaud, P. Meier, J. Org. Chem. 2000, 65, 6770-6772.

[15] W. Jiang, J. Wanner, R. J. Lee, P.-Y. Bounaud, D. L. Boger, J. Am. Chem. Soc. 2003, 125, 1877-1887.

[16] J. A. Gómez-Vidal, M. T. Forrester, R. B. Silverman, Org. Lett. 2001 3, 2477-2479.

[17] V. F. Pozdnev, Tetrahedron Lett. 1995, 36, 7115-7118.

[18] L. N. Mander, C. M. Williams, Tetrahedron 2003, 59, 1105-1136.

[19] C. A. G. N. Montalbetti, V. Falque, Tetrahedron 2005, 61, 1082710852.

[20] B. Belleau, G. Malek, J. Am. Chem. Soc. 1968, 90, 1651-1652.

[20] Y. J. Kim, H.-J. Kim, G.-W. Kim, K. Cho, S. Takahashi, H. Koshino, W.-G. Kim, J. Nat. Prod. 2016, 79, 2223-2228.

[22] R. Müller, S. Hüttel, G. Testolin, J. Herrmann, T. Planke, F. Gille, M. Moreno, M. Stadler, M. Brönstrup, A. Kirschning, Angew. Chem. Int. Ed. n.d., n/a-n/a.

[23] D. Trauner, B. Cheng, R. Müller, Angew. Chem. Int. Ed. n.d., n/a-n/a.

[24] M. Mergler, F. Dick, B. Sax, P. Weiler, T. Vorherr, J. Pept. Sci. 2003, $9,36-46$. 
WILEY-VCH

\section{COMMUNICATION}

Bioactivity-guided guided mass spectrometric networking of extracts from a Xanthomonas strain lead to the discovery of eight new albicidin derivatives and their total synthesis allowed the conformation of their structure and antibacterial activity.

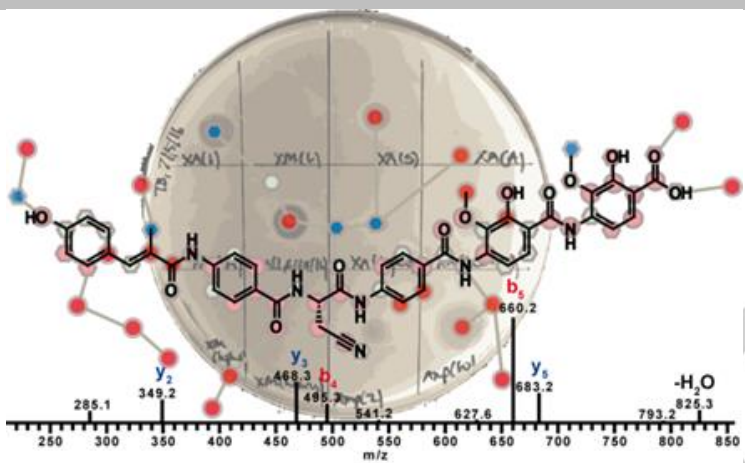

Leonard von Eckardstein," Daniel Petras, " Tam Dang, Stéphane Cociancich, Souhir Sabri, Stefan Grätz, Dennis Kerwat,Maria Seidel, Alexander Pesic, Pieter C. Dorrestein, Monique Royer, John B. Weston, and Roderich $D$. Süssmuth ${ }^{\star}[$ Page No. - Page No.]

Total synthesis and biological assessment of novel albicidins discovered by mass spectrometric networking 